\title{
Objective Predictors of Functional Recovery Associated with Intercostal Nerves Transfer for Triceps Reinnervation in Global Brachial Plexus Palsy
}

\section{Fatores preditores da recuperação funcional associada à transferência de nervos intercostais para reinervação do tríceps em paralisias completas do plexo braquial}

Leandro Pretto Flores ${ }^{1}$

${ }^{1}$ Department of Neurosurgery, Hospital das Forças Armadas, Brasília, DF, Brazil

Arq Bras Neurocir 2016;35:271-278
Address for correspondence Leandro Pretto Flores, PhD, Hospital das Forças Armadas, Brasília, Estrada Contorno do Bosque, s/n - Sudoeste, 70658-900, DF, Brazil (e-mail: leandroprettoflores@hotmail.com).

\begin{abstract}
Keywords

- brachial plexus

- brain plasticity

- nerve transfer

- triceps palsy
\end{abstract}

\section{Resumo}

Objective To evaluate the predictors of functional recovery associated with the transfer of intercostal nerves (ICNs) to the branch innervating the long head of the triceps (BLHT).

Methods A retrospective analysis of 14 patients with global brachial plexus palsy for whom the surgical planning included the transfer of 2 or 3 ICNs to the BLHT.

Results The effective rate of functional recovery for elbow extension was $28 \%$. Surgical timing, severity of the injury, and number of ICNs did not show significance for functional recovery. Patients who underwent ICN transfer for reanimation of elbow extension in combination with phrenic nerve (PN) transfer for reinnervation of elbow flexion, or shoulder stability, obtained poorer results regarding triceps recovery $(p<0.01)$.

Conclusions Intercostal nerves are reliable donors for reinnervation of the triceps in global brachial plexus injuries. However, this technique should be avoided in patients in whom the PN has been transferred for elbow flexion or shoulder abduction.

Objetivos Avaliar os fatores preditores para recuperação funcional associados à transferência de nervos intercostais (NICs) para o ramo do nervo radial que inerva da cabeça longa do tríceps (RCLT).

Métodos Análise retrospectiva de 14 pacientes com paralisia completa do plexo braquial, para os quais o planejamento cirúrgico incluiu a transferência de 2 ou 3 NICs para o RCLT.

Resultados A taxa de recuperação da extensão do cotovelo foi de $28 \%$. O intervalo cirúrgico, a gravidade da lesão e o número de NICs usados não demonstraram significância para a recuperação funcional. Os pacientes nos quais a transferência de NIC foi usada para recuperação da extensão do cotovelo concomitantemente à transferência do nervo frênico para reanimação da flexão do cotovelo ou para received July 25, 2016 accepted

September 22, 2016

published online

November 1, 2016
DOI http://dx.doi.org/ 10.1055/s-0036-1593837. ISSN 0103-5355.
Copyright (c) 2016 by Thieme-Revinter

Publicações Ltda, Rio de Janeiro, Brazil
License terms

(ㄷ) (i) $\ominus$ (\$) 


\author{
Palavras-Chave \\ - plexo braquial \\ - plasticidade cerebral \\ - transferência de \\ nervos \\ - paralisia do tríceps
}

estabilização do ombro obtiveram piores resultados quanto a reinervação do tríceps $(p<0.01)$.

Conclusões Os NICs podem ser utilizados como doadores para reinervação do tríceps em lesões completas do plexo braquial. No entanto, essa técnica deve ser evitada em pacientes nos quais o nervo frênico foi transferido conjuntamente visando a recuperação da flexão do cotovelo ou a estabilização do ombro.

\section{Introduction}

The brachial plexus is involved in 10 to $20 \%$ of all the traumatic injuries of peripheral nerves. Closed traction is the most common mechanism in adults, which is mainly caused by high-energy forces, such as motorcycle accidents. Our previous study regarding epidemiological data of brachial plexus trauma demonstrated that the incidence in our local population is 1.75 cases/100,000 inhabitants per year. ${ }^{1}$ Several different techniques have been proposed for brachial plexus reconstruction, including neurolysis, nerve grafting, nerve transfer, tendon transfer, free muscle transplantation, or nerve root replantation. ${ }^{2}$ To date, there is no standardized surgical protocol determining the best treatment to be offered for patients sustaining such injuries, and the operative planning is mainly based on the surgeon's experience and the needs of the patient. ${ }^{3}$

Elbow extension is required for the upper limb to oppose gravity. The need for extension of the forearm typically includes exercises as swimming or throwing a ball, and it is especially useful to reach overhead objects reliably or working with instruments over a table. ${ }^{4}$ Recently, the interest in elbow extension restoration in cases of total or partial lesions of the brachial plexus has increased, and several surgical procedures have been proposed for reinnervation of the triceps. ${ }^{5-7}$ Nerve transfer is the most frequent technique employed in such scenarios, and the intercostal nerves (ICNs) have been increasingly used as donors to achieve such goal. ${ }^{8,9}$ The results obtained from different authors in using ICNs to restore the triceps function are highly controversial; the British Medical Research Council (MRC) grading system $(0-5)$ was used to evaluate triceps recovery, and outcomes grade M3 or better have been reported ranging from 0 to $81 \%$ of the cases. ${ }^{10-12}$ The reasons for such discrepancy had not been studied, but some authors $\mathrm{s}^{7,10,11}$ have already suggested that the timing for surgery (more or less than six months post-trauma), the severity of the injury (scored by the number of root avulsions of each case), the type of injury (flail arm versus hand function saving injuries), or the age of the patients (younger or older than 40 years-old) may play a role in determining better or poorer outcomes.

Our protocol for treatment of severe injuries of the brachial plexus includes reanimation of elbow flexion, shoulder stability, hand sensory protection, and also elbow extension. We have tried several different donors for reinnervation of the triceps, and obtained good outcomes with most of them. However, our results regarding the transfer of ICNs for triceps reanimation are usually very disappointing.
Thus, the aim of this study is to evaluate our results by transferring two or three ICNs to the branch of the long head of the triceps (BLHT) in patients sustaining global brachial plexus injuries (flail arm) in order to determine which are the possible predictors for good functional recovery when using such technique.

\section{Methods}

From 2004 to 2014, we treated surgically 212 cases of traumatic brachial plexus palsy in adults, 145 of which sustained a flail arm. This retrospective study includes only those patients who demonstrated a total brachial plexus injury associated with complete elbow extension palsy, and for whom the technique for restoring the triceps function included the transfer of two or three ICNs to the BLHT. Subjects with combined cervical spinal cord injuries were excluded, as well as cases sustaining injuries in which the function of the hand was considered complete or partially preserved. Written informed consent was obtained from each participant, and the study was performed in accordance with the Declaration of Helsinki II.

Surgery was recommended for patients who had no signs of spontaneous recovery three months after the trauma and for the patients admitted later with a fixed deficit. The general operative planning for these cases included reanimation of shoulder stability and elbow flexion as the primary goals of the surgery. Finger flexion and hand sensory recovery was eventually attempted in some patients.

Preoperative assessment included nerve conduction studies, electromyography, computed tomography myelogram (CT myelogram), and/or magnetic resonance imaging (MRI). Comparisons between the patients who reached fair (M0 to M2) or good (M3 and M4) outcomes were performed using the Fisher exact test and probability values lower than 0.05 were considered significant.

The following parameters were analyzed to identify predictors of functional recovery associated with the technique of ICN-BLHT: a) surgical timing, specifically, if the surgery was performed before or after sixth months following the trauma; b) the number of ICNs used for the transfer, that is, two or three ICNs as donors; c) the severity of the injury; the number of nerve roots avulsed was chosen as an index to estimate the degree of the stretching forces applied to the brachial plexus structures, considering that the more force is applied to the plexus, the greater the number of avulsed roots and, consequently, the greater the severity of the 
trauma. Thus, a larger number of preganglionic injuries would predict a more powerful mechanism of injury, and a larger number of postganglionic ruptures would predict the opposite. This method is used in our department as a simplification of the scoring system previously described by Terzis et $\mathrm{a}^{13}$ for grading the severity of the brachial plexus injury, since we only considered three possible types of nerve lesions: root avulsion, extra-foraminal nerve rupture, or normal. In addition, the total numbers of pre and postganglionic lesions were respectively divided by the number of cases enrolled in each cohort, obtaining a number considered as a mean of root avulsion and nerve rupture for each group; and finally, d) the type of technique used for reanimation of elbow flexion and shoulder stability, i.e., cases in which the phrenic nerve (PN) was employed as donor for the musculocutaneous nerve (MCN) or for the axillary nerve (AN) compared with those patients in whom the PN was not used as donor. This parameter was tested as a predictor for elbow extension recovery to analyze the ability of the mechanisms involved with neuroplasticity in compensating the reinnervation of two antagonistic functions (elbow flexion/elbow extension) by activating one single cortical area (the cortical area for volitional breathing control).

\section{Surgical Technique (-Fig. 1)}

Under general anesthesia without the use of muscle relaxant drugs, the patient was placed in a supine position and the affected upper limb was positioned abducted on an arm table. We employed a continuous thoracobrachial incision, beginning at the inferior border of the pectoral major muscle, beneath the nipple in men or under the breast in women. The incision followed the curve of the latissimus dorsi up to the axilla, crossing it with a Z-plasty, and finally made at the medial aspect of the arm, under the inferior border of the biceps. The ICNs T3, $\mathrm{T} 4$ and $\mathrm{T} 5$ (or T4 and T5) were isolated in the chest incision, the rib cage was exposed by reflection of the latissimus dorsi and

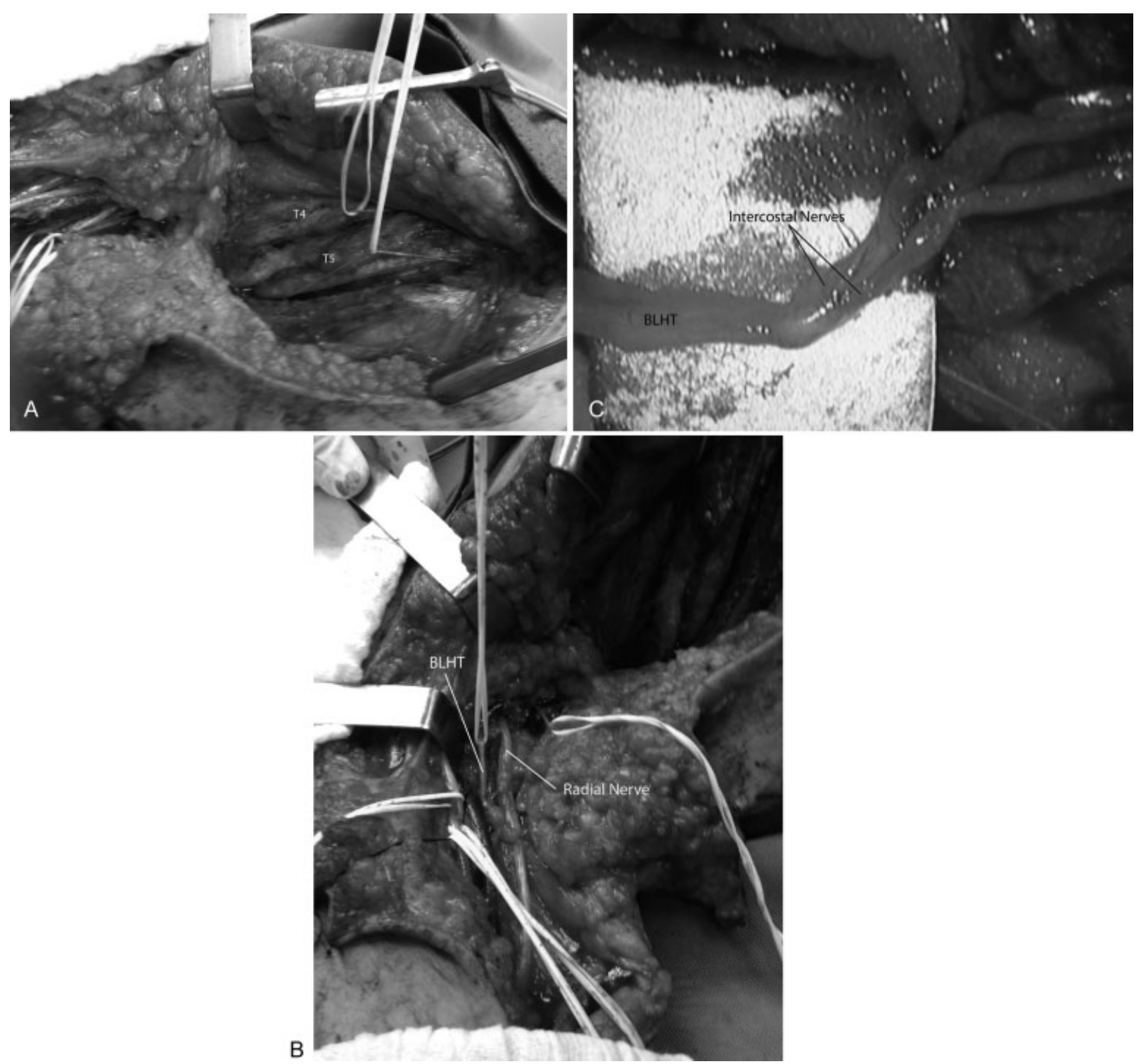

Fig. 1 Surgical approach for the ICN-BLHT transfer on the right side. (A) The intercostal nerves (ICNs) T4 and T5 were dissected free. (B) On the arm incision, the radial nerve and the branch to the long head of the triceps (BLHT) were isolated. (C) Microscopic vision of the cooptation of two intercostal nerves (ICNs) and the branch to the long head of the triceps (BLHT). 
the serratus muscles; the periosteum of each rib was reflected and pulled downward, and the respective ICN was dissected free over its entire anterior course and transected as far distal as possible (-Fig. 1a). Motor responses from each donor nerve were checked by using electrical stimulation. The radial nerve and the BLHT were dissected using the axillary and brachial approaches. The radial nerve was isolated at the point where it runs superficial to the lower border of the subscapularis muscle, and the BLHT was traced distally and proximally - to extend its length for rerouting - and transected at the level of its branching point from the radial nerve (-Fig. 1b). The selected ICNs were coopted to the BLHT by using only fibrin glue, under microscopic magnification (- Fig. 1c).

\section{Follow-up}

Postoperatively, the affected upper extremity was immobilized in a sling for three weeks, with the elbow flexed to $90^{\circ}$. Intense physiotherapy training followed. Initially, passive exercises were encouraged to prevent joint contractures. As soon as the first contractions of the triceps were seen, self-nerve stimulation was undertaken by asking the patient to perform forceful inspiration while attempting to actively extend the elbow. At each postoperative clinic visit throughout follow-up, the MRC grading system was used to score the triceps strength. The muscle was tested against both gravity and resistance, with the shoulder positioned at $90^{\circ}$ of anterior flexion and the patient lying supine.

\section{Results}

This retrospective study includes 14 adult patients meeting the criteria for inclusion specified earlier. Initially, 19 pa- tients were identified as having undergone triceps reinnervation by using ICNs as donors; however, five subjects did not meet the inclusion criteria because two of them were lost to follow-up and three subjects sustained a partial injury. There were 12 males and 2 females, and the mean age of the group was 29.3 years old (range 22-41 years old). The mean time interval from injury to surgery was 6 months (range 3-10 months) and the mean postoperative follow-up time was 26.3 months (range 20-31 months).

The spinal accessory to suprascapular nerve transfer was the most frequent technique used for reinnervation of the shoulder; and the phrenic nerve (PN) targeting the musculocutaneous nerve or the anterior division of the upper trunk (ADUT) were the main techniques employed to recover elbow flexion. Contralateral C7 nerve root to median nerve transfer was the technique employed for reinnervation of the hand only.

- Table 1 summarizes the data regarding preoperative parameters and the outcomes of each case. In 4 patients, we employed 3 ICNs to reinnervate the triceps (28.5\%), and in 10 cases $(71.5 \%)$, only 2 were used. Outcomes regarding elbow extension recovery were registered as MRC grade M4 in two cases (14\%), M3 in two (14\%), M1 in three subjects (21\%), and seven patients did not demonstrate any recovery (M0, 50\%).

General comparisons between the patients who reached poor (M0 to M2) and good (M3 and M4) outcomes for elbow extension recovery are demonstrated in - Table 2 . There were no significant differences between the groups regarding preoperative parameters as age, interval between trauma and surgery, or the severity of the injury. The groups were also not statistically different regarding the use of two ICNs as donors for the nerve transfer. However, we observed that the patients in whom the PN was concomitantly used as

Table 1 Epidemiological, surgical and postoperative data from 14 patients who underwent brachial plexus reconstruction

\begin{tabular}{|c|c|c|c|c|c|c|c|}
\hline Patient & $\begin{array}{l}\text { Age } \\
(\mathrm{Y} / \mathrm{O})\end{array}$ & Type of injury & $\begin{array}{l}\text { Number } \\
\text { of ICN }\end{array}$ & Associated technique & $\begin{array}{l}\text { Follow Up } \\
\text { (months) }\end{array}$ & $\begin{array}{l}\text { Results } \\
\text { elbow } \\
\text { extension }\end{array}$ & $\begin{array}{l}\text { Results } \\
\text { elbow } \\
\text { flexion }\end{array}$ \\
\hline 1 & 23 & RA 5,6,7; RR8,1 & 3 & Phr-MC, XI-SE, CC7-MN & 25 & M0 & M3 \\
\hline 2 & 29 & RA 5,6; RR 7,8,1 & 3 & Phr-ADUT, XI-SE, CC7-MN & 30 & M0 & M4 \\
\hline 3 & 34 & RA $5,6,7,8,1$ & 3 & CC7-MC, XI-SE & 22 & M3 & M3 \\
\hline 4 & 41 & RA $5,6,7,8,1$ & 3 & Phr-MC, XI-SE, CC7-MN & 31 & M1 & M4 \\
\hline 5 & 25 & RR 5, RA 6,7,8,1 & 2 & C5-MC, XI-SE, CC7-MN & 20 & M0 & M3 \\
\hline 6 & 22 & RR 5,6,7; RA 8,1 & 2 & C5-ADUT, Phr-PDUT, C6,C7-RN, XI-SE & 30 & M0 & M3 \\
\hline 7 & 25 & RA $5,6,7,8,1$ & 2 & Phr-MC, XI-SE, CC7-MN & 29 & M0 & M3 \\
\hline 8 & 36 & RR 5,6; RA 7,8,1 & 2 & C5-MC, C6-PDUT, XI-SE, CC7-MN & 22 & M3 & M4 \\
\hline 9 & 31 & RR 5; RA 6,7,8,1 & 2 & C5-MC, XI-SE,CC7-MN & 31 & M4 & M3 \\
\hline 10 & 28 & RA 5,6; RR 7,8,1 & 2 & C7-ADUT, Phr-PDUT, XI-SE, CC7-MN & 30 & M1 & M2 \\
\hline 11 & 30 & RA $5,6,7,8,1$ & 2 & Phr-MC, XI-SE, CC7-MN & 28 & M0 & M3 \\
\hline 12 & 34 & RA 5,6,7,8 RR 1 & 2 & Phr-MC, XI-SE, ICBN-MN & 24 & M0 & M4 \\
\hline 13 & 27 & RR 5,6,7;RA 8,1 & 2 & C5-ADUT, C6-Ax, C7-RN & 23 & M4 & M3 \\
\hline 14 & 26 & RR 5 RA $6,7,8,1$ & 2 & C5-MC, Phr-PDUT, XI-SE, CC7-MN & 24 & M1 & M3 \\
\hline
\end{tabular}

Abbreviations: ADUT, anterior division of the upper trunk; Ax, axillary nerve; CC7, contralateral C7 nerve root; ICBN, intercostobrachial nerve; MC, musculocutaneous nerve; MN, median nerve; PDUT, posterior division of upper trunk; Phr, phrenic nerve; RA, root avulsion; RN, radial nerve; RR, root rupture; SE, suprascapular nerve; $\mathrm{XI}$, spinal accessory nerve. 
Table 2 Comparison between patients who attained poor (M0 to $M 2$ ) and good (M3 to M4) outcomes for elbow extension among 14 patients with global brachial plexus injuries

\begin{tabular}{|l|l|l|l|}
\hline & $\begin{array}{l}\text { M0-M2 } \\
(\mathbf{n}=\mathbf{1 0})\end{array}$ & $\begin{array}{l}\text { M3-M4 } \\
(\mathbf{n}=\mathbf{0 4})\end{array}$ & $p$ \\
\hline Age (mean - years old) & 25.8 & 24.2 & 0.066 \\
\hline $\begin{array}{l}\text { Interval trauma-surgery } \\
\text { (mean - months) }\end{array}$ & 6.1 & 7.2 & 0.073 \\
\hline $\begin{array}{l}\text { Type of injury } \\
\text { (mean - number of } \\
\text { nerve root avulsed) }\end{array}$ & 3.7 & 3.5 & 0.062 \\
\hline $\begin{array}{l}\text { Two intercostals as } \\
\text { donor (n/\%) }\end{array}$ & $7(70 \%)$ & $3(75 \%)$ & 0.092 \\
\hline $\begin{array}{l}\text { Use of phrenic nerve } \\
\text { as donor } \\
\text { (number of patients) }\end{array}$ & 9 & 00 & $<0.001^{*}$ \\
\hline
\end{tabular}

*Statistically significant.

donor for the MCN/ ADUT (6 cases), or posterior division of upper trunk (PDUT)/axillary nerve (3 cases), obtained much poorer results regarding elbow extension recovery than those in which this nerve was not employed to reanimate elbow flexion or shoulder stability, and statistical differences were demonstrated $(p<0.01)$. Otherwise, from the 5 patients in which the PN was not employed as donor for reconstruction of the brachial plexus, 4 of them attained results as M3 or M4 for elbow extension (90\%), and only one demonstrated no recovery $(p=0.017)$.

The role of the number of ICNs used in the transfer as a technical parameter in determining good or fair outcomes is demonstrated in - Fig. 2. Seventy-five percent of the four cases in which three ICNs were employed as donor achieved outcomes graded as M0 or M2, and 25\% as M3 or M4; for the 10 cases in which 2 ICNs were used for reanimation of the BLHT, 70\% reached strength of M0 or M1 for elbow extension, and 30\% reached M3 or M4. There were no significant

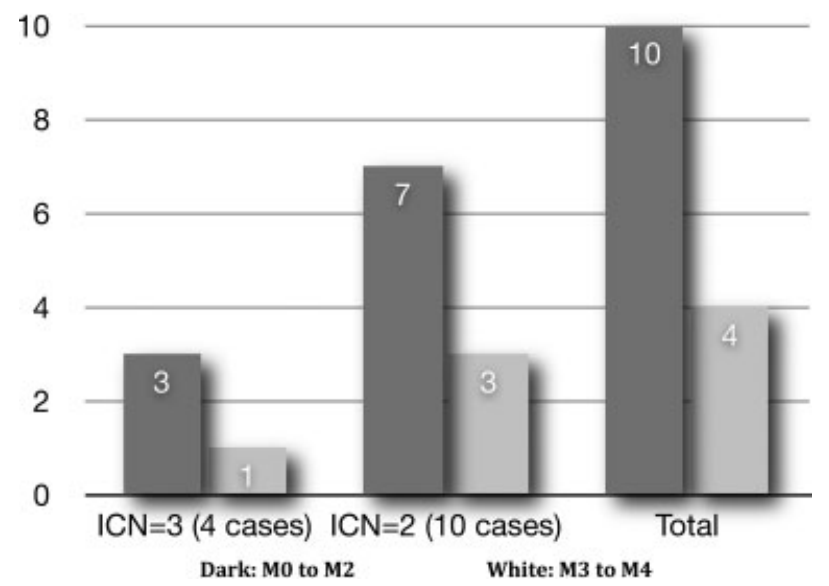

Fig. 2 Comparison between fair (M0 to M2) and good ( $M 3$ to M4) outcomes in patients submitted to a transfer of three or two intercostal nerves (ICNs) for reanimation of the triceps.

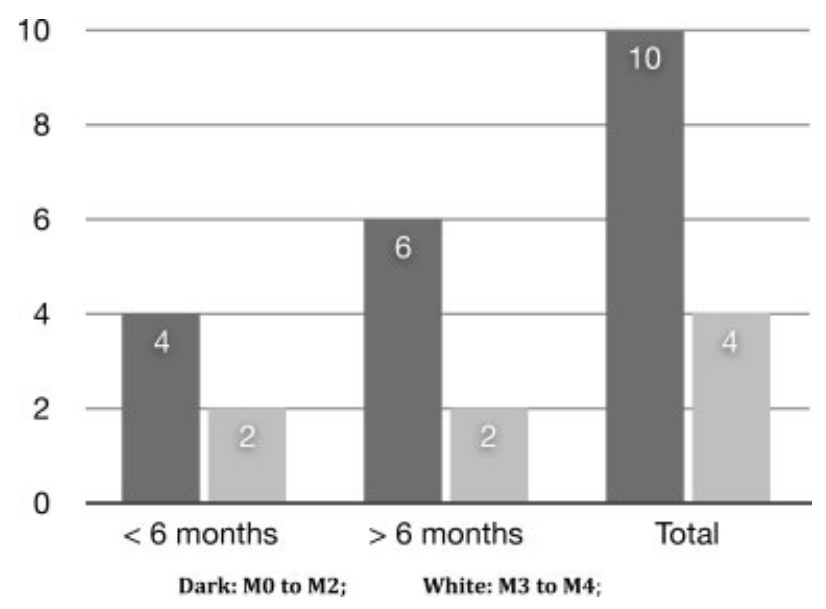

Fig. 3 Comparison between fair (M0 to M2) and good (M3 to M4) outcomes in patients whose interval between trauma and surgery was less or more than six months.

differences regarding good $(p=0.081)$ and fair results $(p=0.073)$.

-Fig. 3 shows the influence of the surgical timing on the outcomes. There were 6 patients who underwent surgery before the 6th month following the trauma; sixty-six percent of them achieved outcomes graded as M0 or M1, and 34\% as M3 or M4. For the remaining 8 cases that were operated on later, $75 \%$ did not attain functional recovery, and $25 \%$ recovered good elbow extension. No statistical difference between the groups (fair: $p=0.078$; good: $p=0.086$ ) was observed.

Finally, the severity of the injury was tested to evaluate its importance in determining the outcomes, as demonstrated in -Fig. 4. The entire cohort was divided between those 10 cases that achieved fair results (M0 and M1) and the 4 subjects that attained good outcomes (M3 and M4) for elbow extension, and the total number of root avulsions and nerve ruptures was summed for each group. Root avulsions represented $72 \%$ of the type of injury in patients that did not recover triceps function, predicting a severe type of lesion for these cases. However, they

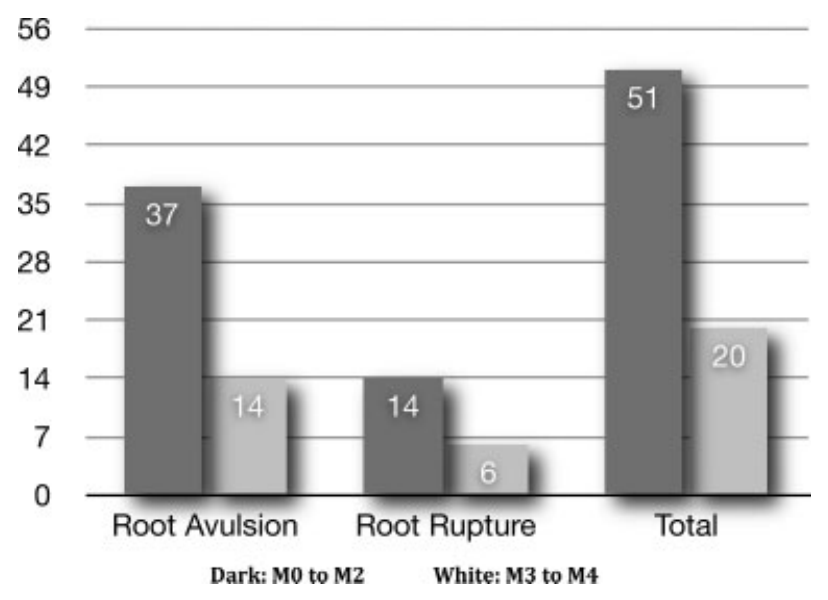

Fig. 4 Comparison between fair (M0 to M2) and good (M3 to M4) outcomes regarding the severity of the injury, determined by the total number of root avulsions and nerve ruptures in each group. 
also correspond to $70 \%$ of the type of the injury in subjects who showed good elbow extension restoration. There was no significant difference between these groups regarding the severity of the trauma ( $p=0.075$ ). There was also no statistical significant difference between those who reached respectively fair or good outcomes regarding the means for root avulsion (3.7 versus 3.5, $p=0.062$ ) or for extra-foraminal nerve rupture (1.4 versus 1.5 , $p=0.087$ ).

The average time for the first triceps contraction was 18 months (range 15-21 months). The average time required to achieve extension against gravity was 25 months (range 20-33 months). No patient complained of symptoms or signs of respiratory insufficiency, and no postoperative respiratory complication was observed. However, in those patients in whom the PN was used as donor for other recipient nerves, the postoperative radiological examination of the chest demonstrated that the hemi diaphragmatic dome from the side of the transected nerve persisted elevated during the entire follow-up period in all of the cases.

\section{Discussion}

\section{Nerve Transfers for the Triceps: What For and How to} Achieve It

Historically, elbow extension recovery has not been considered of much importance regarding functional outcomes in global brachial plexus injuries ${ }^{14}$; however, an active extension of the forearm is needed to perform actions that oppose gravity, such as reaching objects above the level of the head. The primary neurological microsurgery of the brachial plexus is the best opportunity to recover the triceps function in patients sustaining such injuries, since it is very difficult to restore it with palliative surgeries. ${ }^{15}$ Thus, our regular plan for the reconstruction of a totally injured brachial plexus includes nerve grafting, targeting the anterior division of the upper trunk, or the MCN from proximal nerve roots - in cases in which these latter structures are available, or using the PN as donor in patients sustaining multiple root avulsion; transfer of the spinal accessory nerve to the suprascapular nerve; in some circumstances, the $\mathrm{PN}$ is employed for reinnervation of the posterior division of the upper trunk or the axillary nerve; reconstruction of sensory and motor hand function by using the contralateral $\mathrm{C} 7$ nerve root, that is transferred to the median nerve and bridged by a pedicle ulnar nerve; and also ICN-BLHT transfer, aiming to restore elbow extension.

Terzis and Barmpitsioti ${ }^{11}$ published a large series of triceps reinnervation for brachial plexus palsy in adult patients - 156 cases and 232 motor donors - and achieved a global rate of only $31.7 \%$ of good results (M3 or M4). Intraplexual donors - as proximal nerve roots, upper trunk and posterior cord - and extraplexual donors, including the cervical plexus, spinal accessory, ICN, and also PN, were used to reinnervate the radial nerve. Zheng et al also reported poor results (M0 to M2) by transferring three ICN to the nerve for triceps in all of their seven patients. On the other hand, by transferring three ICN to the BLHT, Goubier et al $^{12}$ attained elbow extension strength graded as M4 in 7 of 11 patients with total brachial plexus palsy; and by using two or three ICN as donor to the BLHT, Gao et $\mathrm{al}^{16}$ obtained good outcomes in approximately half of their 25 cases. Doi et $\mathrm{al}^{4}$ reported relevant triceps muscle recovery in 14 of 26 patients in whom ICN to triceps transfer was combined with double free muscle transplantation. In 2010, we described our initial series of reinnervation of the triceps, observing good outcomes in $76 \%$ of 25 consecutive cases sustaining partial and global brachial plexus injuries, by employing different donors such as ipsilateral C7 nerve root, phrenic, medial pectoral, spinal accessory, and intercostal nerves, as well as the posterior cord and ulnar nerve. ${ }^{7}$ In another study, we selected 21 patients sustaining isolated upper root injuries, and triceps recovery scored as M3 or better was noted in $85 \%$ of the cases by using donors as the medial pectoral nerve, motor fascicles from the ulnar nerve, or fascicles from the radial nerve. ${ }^{17}$ Recently, Wang et al ${ }^{18}$ proposed the transfer of the PN to the posterior division of the lower trunk for recovering elbow extension, and reported good outcomes in $81 \%$ of 27 cases.

\section{Predictors of Elbow Extension Recovery: How to Evaluate our Results?}

In the study presented herein, we selected 14 cases in which the pattern of functional recovery of elbow extension following the surgery for total brachial plexus palsy could be well evaluated, aiming to determine which would be the possible pitfalls resulting from the technique of using ICNs as donors for reinnervation of the triceps. Our overall results demonstrated very poor outcomes, since only $28 \%$ of the patients reached strengths for extension of the elbow graded as M3 or M4. These results are highly contrasting to our own outcomes obtained by using other donors, as the PN $(80 \%)^{7}$, the medial pectoral nerve $(100 \%),{ }^{19}$ or motor fascicles from the radial nerve $(93 \%)^{20}$, these two latter techniques used for cases sustaining partial injuries. They are also different from those reported by Goubier et $\mathrm{al}^{12}$ and Gao et $\mathrm{al}^{16}$, but in accordance with the results of Zheng et $\mathrm{al}^{10}$ and Malungpaishrope et al. ${ }^{9}$

The reasons for such poor results were studied by comparing patients that achieved good with those that attained poor outcomes. It was noted that the severity of the trauma what in these study was scored by the number of avulsed roots identified for each case - did not shown to be a useful predictor, since multiple root avulsions were observed with the same frequency either in the individuals that recovered as in those that did not recover a strong elbow extension. The timing for the surgery was also not identified as a parameter that influenced directly the surgical results, since poor outcomes for elbow extension were distributed with the same frequency among those who underwent surgery before or after six months following the trauma.

The number of ICNs used for the transfer was also evaluated as a predictor for better outcomes; previous reports detailed the number of fibers of a single ICN as being from 500 to 700 myelin-coated fibers ${ }^{21}$; thus, 3 of them were supposed to provide the BLHT with sufficient amount of motor axons that would allow a functional triceps recovery. 
However, the study of Gao et $\mathrm{al}^{16}$ showed no difference in obtaining good outcomes regardless of the use of either two or three ICNs for the transfer, and we also could not observe any difference in outcomes by using one more ICN as donor in patients with total palsy of the brachial plexus.

Otherwise, this short cohort was able to identify that the concomitant use of the PN for recovering biceps or shoulder function and the use of ICN transfer for reanimation of the triceps demonstrated to be an important parameter for downgrading the final outcome for the elbow extension strength. None of the individuals in which the PN was employed for reanimation of elbow flexion or shoulder stability recovered useful elbow extension; on the other hand, in those 5 patients in whom this nerve was not employed as donor, $90 \%$ of them recovered some triceps function considered as functional. In our opinion, the inability of the brain in coordinating antagonistic functions - as elbow flexion and elbow extension by activating the cortical center for control of volitional breathing is the most likely cause for the observed failures.

\section{The Mechanisms of Neuroplasticity and How They May Limit the Outcomes of Nerve Transfer Techniques}

The adaptations of the central nervous system considered of utmost importance for the study of the mechanism of neuroplasticity that follows any nerve transfer technique are those related to the primary connections of cortical motor neurons to spinal motor neurons via the corticospinal tact. Some structural neuronal modifications at the level of the brain cortex and reconnection between different areas of the motor and sensory areas may explain how volitional control of the muscles innervated by different nerves can be achieved by using nerve transfer techniques to restore motor and sensory functions. ${ }^{22,23}$ Malessy et $\mathrm{al}^{24}$ studied the neural mechanism of plasticity that follows the transfer of the ICN to the MCN. They concluded that the late volitional and independent control of the biceps is probably obtained via newly created reconnections between cortical neurons from the biceps area with those neurons located at the primary cortical area that coordinate respiratory movements (rib cage muscles control), via activation of a network of interneurons. These interneurons are previously silent, subthreshold, or even some of those involved in postural control over the rib cage (once stabilization of the thorax is an essential prerequisite for arm movement). They become active as consequence of the modifications of the central motor program that follows the relearning training necessary to activate the reinnervated muscle via a nerve transfer technique. The same type of reconnections may be observed following transfers of the PN to the MCN. Studies with positron emission tomography (PET) and functional magnetic resonance imaging (FMRI ) have precisely mapped the location of the areas for the biceps and for the triceps muscles on primary sensorimotor cortices, ${ }^{25}$ and the area for volitional breathing control. ${ }^{26}$ However, to date, none of these studies were able to identify distinct areas specific for the intercostal muscles and for the diaphragm. ${ }^{27} \mathrm{We}$ inferred that the ICN and the PN might be controlled by some different network of neurons from the motor cortex, but they both control respiratory movements by acting coordinately. Considering that the mechanism of neuroplasticity involves the activation of silent connections between different cortical motor neurons, we can also predict that the central motor planning may privilege some reconnections of brain areas involved with functions considered more crucial for survival. We hypothesize that, as elbow flexion is more frequently used in daily life activities and involved in the mechanism of feeding in humans (bringing the food to the mouth), the mechanisms of cerebral plasticity may privilege to recover this function and to repress its antagonistic action, that is, the elbow extension. In other words, it would be anatomically possible to reconnect the primary area for the biceps and the area for the triceps to the cortical center for volitional control of breathing (that activates the PN and ICN) at the same time; however, in many cases, the brain may prioritize a connection with the neurons that control the biceps instead of those for the triceps.

This neurophysiological mechanism may explain why our patients in whom the PN was employed for restoration of elbow flexion recovered the biceps better than the triceps. Reinnervation of the triceps was observed in some of our patients in whom the PN targeted the biceps; however, these patterns of recovery were always nonfunctional (MRC M1). It is acceptable to infer that in these cases the brain may have privileged the flexion instead of the extension of the elbow. Zheng et $\mathrm{al}^{10}$ observed the same phenomenon in their short series of seven cases with concomitant transfer of the PN to elbow flexion and the ICN to elbow extension, as none of them attained functional triceps recovery. Otherwise, Gao et $\mathrm{al}^{16}$ reported that $50 \%$ of their cases attained elbow extension strength graded as M3 or better, in 25 subjects in whom the PN was transferred to the MCN and two ICNs were transferred to the BLHT. It suggests that the mechanism of neuroplasticity involved in the reorganization of the brain cortex to activate antagonistic functions may not represent as an ultimate barrier for the full recovery of these patients, although it may determine failures in some of them. Further studies might assess whether brain stimulation techniques (as transcranial magnetic stimulation) may play a role in benefiting such patients, by forcing the creation of novel connections between different brain areas and finally improving the power for elbow flexion and extension.

\section{Conclusions}

Based on this short series of cases, we suggest that ICNs may be considered as reliable donors for reinnervation of the triceps in patients sustaining global brachial plexus injuries. However, this technique should be avoided in those cases in which the PN was employed as donor for restoring other functions, as elbow flexion or shoulder stability. Also, in agreement with other studies, we suggest 
that the use of two ICNs may attain similar outcomes as using three nerves as donors. The surgical timing and the severity of the injury did not affect the outcomes in our cohort; however, because of the small sample of our enrolled patients, one should be conservative in extrapolating these results.

\section{References}

1 Flores LP. [Epidemiological study of the traumatic brachial plexus injuries in adults]. Arq Neuropsiquiatr 2006;64(1):88-94

2 Songcharoen P. Management of brachial plexus injury in adults. Scand J Surg 2008;97(4):317-323

3 Belzberg AJ, Dorsi MJ, Storm PB, Moriarity JL. Surgical repair of brachial plexus injury: a multinational survey of experienced peripheral nerve surgeons. J Neurosurg 2004;101(3):365-376

4 Doi K, Shigetomi M, Kaneko K, et al. Significance of elbow extension in reconstruction of prehension with reinnervated free-muscle transfer following complete brachial plexus avulsion. Plast Reconstr Surg 1997;100(2):364-372, discussion 373-374

5 Bertelli JA, Santos MA, Kechele PR, Ghizoni MF, Duarte H. Triceps motor nerve branches as a donor or receiver in nerve transfers. Neurosurgery 2007;61(5, Suppl 2):333-338, discussion 338-339

6 Terzis JK, Kokkalis ZT. Restoration of elbow extension after primary reconstruction in obstetric brachial plexus palsy. J Pediatr Orthop 2010;30(2):161-168

7 Flores LP. Triceps brachii reinnervation in primary reconstruction of the adult brachial plexus: experience in 25 cases. Acta Neurochir (Wien) 2011;153(10):1999-2007

8 Goubier JN, Teboul F. Transfer of the intercostal nerves to the nerve of the long head of the triceps to recover elbow extension in brachial plexus palsy. Tech Hand Up Extrem Surg 2007;11(2): 139-141

9 Malungpaishrope K, Leechavengvongs S, Witoonchart K, Uerpairojkit C, Boonyalapa A, Janesaksrisakul D. Simultaneous intercostal nerve transfers to deltoid and triceps muscle through the posterior approach. J Hand Surg Am 2012;37(4):677-682

10 Zheng MX, Xu WD, Qiu YQ, Xu JG, Gu YD. Phrenic nerve transfer for elbow flexion and intercostal nerve transfer for elbow extension. J Hand Surg Am 2010;35(8):1304-1309

11 Terzis JK, Barmpitsioti A. Our experience with triceps nerve reconstruction in patients with brachial plexus injury. J Plast Reconstr Aesthet Surg 2012;65(5):590-600

12 Goubier JN, Teboul F, Khalifa H. Reanimation of elbow extension with intercostal nerves transfers in total brachial plexus palsies. Microsurgery 2011;31(1):7-11
13 Terzis JK, Vekris MD, Soucacos PN. Outcomes of brachial plexus reconstruction in 204 patients with devastating paralysis. Plast Reconstr Surg 1999;104(5):1221-1240

14 Millesi H. Surgical management of brachial plexus injuries. J Hand Surg Am 1977;2(5):367-378

15 Madsen M, Marx RG, Millett PJ, Rodeo SA, Sperling JW, Warren RF. Surgical anatomy of the triceps brachii tendon: anatomical study and clinical correlation. Am J Sports Med 2006;34(11): 1839-1843

16 Gao K, Lao J, Zhao X, Gu Y. Outcome after transfer of intercostal nerves to the nerve of triceps long head in 25 adult patients with total brachial plexus root avulsion injury. J Neurosurg 2013; 118(3):606-610

17 Flores LP. Results of surgical techniques for re-innervation of the triceps as additional procedures for patients with upper root injuries. J Hand Surg Eur Vol 2013;38(3):248-256

18 Wang SF, Li PC, Xue YH, Zou JY, Li WJ, Li Y. Direct Coaptation of the Phrenic Nerve With the Posterior Division of the Lower Trunk to Restore Finger and Elbow Extension Function in Patients With Total Brachial Plexus Injuries. Neurosurgery 2016;78(2):208-215

19 Flores LP. Reanimation of elbow extension with medial pectoral nerve transfer in partial injuries to the brachial plexus. J Neurosurg 2013;118(3):588-593

20 Flores LP. The radio-radial nerve transfer for elbow extension restoration in C5 to C7 nerve root injury. Microsurgery 2012; 32(1):55-59

21 Ploncard P. A new approach to the intercosto-brachial anastomosis in the treatment of brachial plexus paralysis due to root avulsion. Late results. Acta Neurochir (Wien) 1982;61(4):281-290

22 Aminoff MJ, Sears TA. Spinal integration of segmental, cortical and breathing inputs to thoracic respiratory motoneurones. J Physiol 1971;215(2):557-575

23 Anastakis DJ, Malessy MJ, Chen R, Davis KD, Mikulis D. Cortical plasticity following nerve transfer in the upper extremity. Hand Clin 2008;24(4):425-444, vi-vii

24 Malessy MJ, van der Kamp W, Thomeer RT, van Dijk JG. Cortical excitability of the biceps muscle after intercostal-to-musculocutaneous nerve transfer. Neurosurgery 1998;42(4):787-794, discussion 794-795

25 Stephan KM, Fink GR, Passingham RE, et al. Functional anatomy of the mental representation of upper extremity movements in healthy subjects. J Neurophysiol 1995;73(1):373-386

26 Maskill D, Murphy K, Mier A, Owen M, Guz A. Motor cortical representation of the diaphragm in man. J Physiol 1991; 443:105-121

27 McKay LC, Evans KC, Frackowiak RS, Corfield DR. Neural correlates of voluntary breathing in humans. J Appl Physiol (1985) 2003; 95(3):1170-1178 